\title{
The Influence of Marital Status on Survival in Patients with Nasopharyngeal Carcinoma: A Surveillance, Epidemiology, and End Results (SEER) Database Analysis
}

Bin $\mathrm{Yu}$

Mianyang central hospital

Hong Ning

mianyang central hospital

Shan Xu

Universitat Duisburg-Essen

Li Qin

Mianyang Central Hospital

Bin-wei Lin

Mianyang Central Hospital

Fei Lin ( $\square$ loganfeilin@hotmail.com )

the first affiliated of chengdu medical college https://orcid.org/0000-0003-3489-1959

Research article

Keywords: Nasopharyngeal carcinoma, marital status, SEER, survival analysis, subgroup analysis

Posted Date: September 25th, 2019

DOl: https://doi.org/10.21203/rs.2.14775/v1

License: (c) (i) This work is licensed under a Creative Commons Attribution 4.0 International License.

Read Full License 


\section{Abstract}

Purpose: To assess the influence of marital status on survival in patients with nasopharyngeal carcinoma (NPC).

Methods: We used the Surveillance, Epidemiology, and End Results (SEER) database to analyze 5477 patients who were diagnosed with NPC from 2004 to 2016. Kaplan-Meier survival analysis and Cox proportional hazard regression were used to analyze the influences of marital status on cause-specific survival (CSS) and overall survival (OS). Subgroup analyses was used to assess the influences of marital status on CSS based on different factors.

Results: The 5477 patients were divided into three groups, with $61.5 \%, 22.4 \%$, and $16.1 \%$ of patients being married, single/unmarried, and separated/widowed/divorced, respectively. The separated/widowed/divorced group were more likely to be female $(P<0.001)$; had the highest proportion of elderly subjects $(P<0.001)$; were mostly Caucasian $(P<0.001)$; had pathological grading I/II ( $P$ $<0.001)$; were likely to receive surgery $(P=0.032)$; and were registered at the northeast, north central, and south $(P<0.001)$ regions. The 5 -year CSS was $92.6 \%, 92.4 \%$, and $85.1 \%$ in the married, single/unmarried, and separated/widowed/divorced groups, respectively $(P<0.001)$; and respective 5 -year OS was $60.7 \%$, $54.6 \%$, and $40.1 \%$ ( $P<0.001)$. Marital status was the independent prognostic factor for NPC. Compared with married patients, separated/widowed/divorced patients had a significantly increased risk of NPCrelated death (hazard ratio $[\mathrm{HR}]=2.180,95 \%$ confidence interval $[\mathrm{Cl}] 1.721-2.757, \mathrm{P}<0.001$ ). The single/unmarried $(P=0.355)$ group had a similar CSS as that of the group.

Conclusion: Marital status is an independent prognostic factor for survival of NCP patients. Separated/widowed/divorced status increases the risk of NPC mortality; hence, more social and psychosocial support should be given to patients who are separated, widowed, or divorced.

\section{Introduction}

Nasopharyngeal carcinoma (NPC) is a rare and malignant cancer with the highest incidences in SouthEastern Asia, Eastern Asia, Eastern Africa, and Middle Africa[1]. Radiotherapy and chemotherapy remain the most effective treatment options. However, owing to drug-induced toxicity and radiation-related sequelae, patients often experience severe side effects that significantly affect their quality of life and survival[2-4]. Social support plays a very important role in the lives of patients with cancer, especially marital status, which has been confirmed to affect the survival rate in different tumors[5-8]. Understandably, marital status is of significance even for patients with NPC.

A recent study analyzed the 10 leading causes of tumor-related deaths; the results showed a generally significant survival benefit for married patients as compared to unmarried patients. Moreover, the former group had lower risk of early tumor-related death than the latter[5]. Osazuwa-Peters' study of head and neck cancer (HNC) found that being married conferred a survival advantage among HNC survivors, but the study only classified patients as married or unmarried[8]. One Surveillance, Epidemiology, and End 
Results (SEER) database-based study on marital status found that being married had a protective effect on cause-specific survival (CSS) and overall survival (OS) compared to unmarried status. Nevertheless, this study did not compare married patients with specific subgroups of unmarried patients such as single/unmarried and separated/divorced/widowed[9]. The other SEER-based marital status study showed that widowed patients were associated with higher risk of mortality in NPC than married, divorced, or single patients, but the sample size was small. Furthermore, some essential medical data were lacking, which may have had significant effects on patient outcomes with NPC. In addition, it only recorded data from 2004 to 2013 from the SEER database[10]. However, the SEER database has been updated until 2016, and there are few studies on the impact of different marital status on NPC. Therefore, we used patient data of those diagnosed between 2004 and 2016 included in the SEER Cancer Registry to explore in detail the relationship between different marital status and patient survival of patients.

\section{Material And Methods}

\section{Patients}

We extracted data from the SEER database released in April 2016 as the data source for this study. The SEER program is sponsored by the National Cancer Institute and consists of 17 population-based cancer registries that represents approximately $28 \%$ of the US population[11]. The SEER program provides accurate and continuous information on cancer incidence, survival, prevalence, and patient demographics. With the help of the National Cancer Institute's SEER $*$ Stat software (Version 8.3.5; www.seer.cancer.gov/seerstat), patients diagnosed with NPC from 2004 and 2016 were included. The excluded criteria were as follows: (1) age at diagnosis was less than 18 years; (2) unknown survival month; (3) unknown marital status; (4) a prior diagnosis of malignancy; (5) more than one primary site.

\section{Study variables and endpoints}

The following variables were identified from the SEER database: age, sex, ethnicity, pathology grade, primary site, insurance, registry site, year of diagnosis, surgery, and radiotherapy. We divided patients into three categories: "married", "single/unmarried," and "separated/widowed/divorced." The pathology grade was also divided into three groups: well differentiated, grade I and moderately differentiated, grade II; poorly differentiated, grade III and undifferentiated, anaplastic, grade IV; and unknown group. The TNM stage group was derived by the American Joint Committee on Cancer, Cancer Staging Manual (7th edition, 2010), T-stage (T1, T2, T3, T4, or unknown); N-stage (N0, N1, N2, N3, or unknown); M-stage (M0, M1, or unknown).

According to the classification principles of the US Census Bureau, 18 cancer registries were categorized into four regions, namely West, Northeast, North central, and South[12]. The primary sites included six groups, namely superior wall of the nasopharynx, posterior wall of the nasopharynx, lateral wall of the nasopharynx, anterior wall of the nasopharynx, overlapping lesion of the nasopharynx, and nasopharynx. 
Patients were also categorized based on whether they underwent surgery and radiotherapy. The endpoints in this study were the 5-year cause-specific survival (CSS) that was calculated from diagnosis until death due to NPC or last known date alive and the 5-year overall survival (OS) that was calculated as death from any cause.

\section{Statistical analysis}

Patients' baseline characteristics were compared by using the chi-squared $(\chi 2)$ test. We used the KaplanMeier method to estimate the CSS and OS, and the survival differences were calculated by the log-rank test. The binary Cox regression model was calculated using the hazard ratio (HR) for relationships between each variable and mortality. Every variable for which $P<0.05$ in the univariate analyses was initially included in multivariate analyses. Notably, we still included some necessary variables for the Cox proportional hazards regression despite $P>0.05$ in their respective univariate analyses, because they were common confounders of NPC such as T-stage and N-stage. All confidence intervals (Cls) were stated at the $95 \%$ confidence level. Statistical analysis was conducted using SPSS software version 22.0 (IBM Corporation, Armonk, USA). $P$ value $<0.05$ indicated statistical significance.

\section{Results}

\section{Patient baseline characteristics}

Initially, 7380 patient records were extracted between 2004 and 2016 from the SEER database. Based on the inclusion and exclusion criteria, 5477 eligible patients (3886 men and 1591 women) were identified during the 12-year study period. A flow diagram of the study selection is presented in Figure 1. Among these patients, 3370 (61.5\%) were married, 1226 (22.4\%) were single/unmarried, and 881 (16.1\%) were separated/widowed/divorced. Significant differences were noticed in all the comparisons. With respect to sex, men were more likely to be married (74.4\%), while female patients were more likely to be separated/widowed/divorced (44.0\%). The separated/widowed/divorced group were more likely to be female $(P<0.001)$; had the highest proportion of elderly subjects ( $>50$ years, $P<0.001$ ); were mostly Caucasian $(P<0.001)$; had pathological grading I/II $(P<0.001)$; were likely to receive surgery $(P=0.032)$; and were registered at the northeast, north central, and south $(P<0.001)$ sites. Compared with the other groups, married patients were more likely to be in the West registry site, have grade III/IV NPC, and the highest proportion of radiation and chemotherapy history. However, there was no significant difference in primary site cancer among the three study groups. The demographic and clinical characteristics of NPC and treatment types are summarized in Table 1.

\section{Effect of marital status on CSS in the SEER database}

The univariate log-rank test was used to evaluate the 5 -year CSS, which was $92.6 \%, 92.4 \%$, and $85.1 \%$ in the married, single/unmarried, and separated/widowed/divorced, respectively $(P<0.001)$. In the 
multivariate analysis, the HR of the single/unmarried group was lower than that of the married group (HR $=0.811,95 \% \mathrm{Cl}=0.675-1.152, P=0.355)$, and the HR of separated/widowed/divorced group was higher than that of the married group $(\mathrm{HR}=2.180,95 \% \mathrm{Cl}=1.727-2.751, P<0.001)$. The CSS of NPC patients were calculated by Kaplan-Meier curve (Figure 2$)$. In univariate analyses, age $(P<0.001)$, ethnicity $(P<0.001)$, registry site $(P=0.005)$, grade $(P=0.001)$, pathologic T stage $(P=0.001)$, pathologic $\mathrm{N}$ stage $(P<0.001)$, pathologic $\mathrm{M}$ stage $(P=0.003)$, radiotherapy $(P<0.001)$ and chemotherapy $(P<0.001)$ were regarded as significant risk factors for CSS in NPC patients (Table 2). The multivariate analysis was performed by Cox regression, and variables that were validated as independent prognostic factors included age ( $>50$ years, $[\mathrm{HR}=3.878,95 \% \mathrm{Cl}=3.025-4.971, P<0.001])$; other ethnicities $(\mathrm{HR}=0.560,95 \%$ $\mathrm{Cl}=0.451-0.695, P<0.001)$; southern registry site $(\mathrm{HR}=1.531,95 \% \mathrm{Cl}=1.207-1.941, P<0.001)$; pathological grading III/IV $(\mathrm{HR}=0.599,95 \% \mathrm{Cl}=0.441-0.812, P=0.001)$; pathologic $\mathrm{N} 2$ stage $(\mathrm{HR}=$ $0.623,95 \% \mathrm{Cl}=0.463-0.837, P=0.002)$; pathologic $\mathrm{N}$ unknown stage, $(\mathrm{HR}=1.514,95 \% \mathrm{Cl}=1.096-$ 2.091, $P=0.012)$; pathologic $\mathrm{M} 1$ stage $(\mathrm{HR}=1.457,95 \% \mathrm{Cl}=1.004-2.114, P=0.048)$; pathologic $\mathrm{M}$ unknown stage $(\mathrm{HR}=1.550,95 \% \mathrm{Cl}=1.160-2.072, P=0.003)$; no radiotherapy $(\mathrm{HR}=2.460,95 \% \mathrm{Cl}=$ 1.961-3.086, $P<0.001)$; and no chemotherapy $(\mathrm{HR}=2.180,95 \% \mathrm{Cl}=1.778-2.674, P<0.001)$ (Table 2).

\section{Effect of marital status on OS in the SEER database}

We used univariate log-rank test to evaluate the 5-year OS of NPC patients. Patients in the married group had a better 5-year OS (60.7\%) than those who were single/married (54.6\%) and separated/widowed/divorced (40.1\%). The Kaplan-Meier curve was used to calculate the OS of NPC patients (Figure 3). All the differences were significant independent factors for OS among NPC patients according to the univariate log-rank test $(P<0.001)$, including age $(P<0.001)$, ethnicity $(P<0.001)$, sex $(P<0.001)$, registry site $(P<0.001)$, grade $(P<0.001)$, primary site $(P<0.001)$, pathologic T stage $(P<0.001)$, pathologic $\mathrm{N}$ stage $(P<0.001)$, pathologic $\mathrm{M}$ stage $(P<0.001)$, surgery performed $(P<0.001)$, insurance $(P<0.001)$, radiotherapy $(P<0.001)$, chemotherapy $(P<0.001)$, and marital status $(P<0.001)$ (Table 3$)$. The variables that were significant in the univariate log-rank test were validated as independent risk factors by multivariate modeling analysis using Cox regression (Table 3 ). The single/unmarried and separated/windowed/divorced patients had higher $\mathrm{HRs}(\mathrm{HR}=1.219,95 \% \mathrm{Cl}=1.100-1.351, P<0.001$ vs. $\mathrm{HR}=1.977,95 \% \mathrm{Cl}=1.784-2.191, P<0.001$, respectively) than married patients.

\section{Subgroup analysis by age, gender, grade, insurance, surgery, radiation, and chemotherapy}

We analyzed the effects of marital status on CSS according to age, sex, grade, surgery, radiation, and chemotherapy. Interestingly, univariate analysis showed that only married patients of both age groups (i.e., $\leq 50$ years or $>50$ years) had better 5 -year CSS than other patients $(P<0.001)$, although the HRs among unmarried male patients were all higher than those of their female counterparts. Further, patients in the separated/windowed/divorced group had the lowest 5-year survival rate except those that had 
grade I/II stage NPC. Patients in the single/unmarried group had the highest number of surgery-naïve female patients, with unknown grade, and who had not undergone radiotherapy and chemotherapy. Moreover, multivariate analysis showed that the separated/windowed/divorced group had significant differences with respect to all parameters except for the grade $1 /$ II staging and being uninsured, when compared with the married group $(P<0.05)$. The single/divorced group had no significant differences as compared to the married group, except for those that did not receive chemotherapy. The married group and single/unmarried group seemed to have a similar 5-year survival rate in with respect to sex, NPC grade, and history of radiotherapy.

\section{Discussion}

Herein, we evaluated the influence of marital status on survival outcome in patients diagnosed with NPC between 2004 and 2016 based on a SEER-database cohort study; the SEER data was well-matched and had long-term follow-up. Our results showed that married patients have a highest CSS and OS, and the lowest mortality among the study groups. The beneficial influence of married status persisted despite adjusting for age, ethnicity, sex, registry site, grade, primary site, pathologic TNM stage, insurance, surgery, radiotherapy, and chemotherapy. Furthermore, separated/windowed/divorced patients were more likely to have poor survival than other patients. Additionally, subsequent subgroup analysis according to age, sex, grade, surgery, radiation, and chemotherapy based on the SEER stage, validated the prognostic value of marital status in NCP. Hence, being married was suggested to have a protective effect on survival as compared to other marital status; these results were consistent with Huang et al's study[13].

Here, we report several new findings. First, risk of death in the 5-year OS among uninsured patients was obviously higher than insured patients and those on Medicaid $(P<0.001)$ and was not reported in previous studies $[9,10]$. Second, the risk of death in 5-year CSS and OS among primary site tumor in the anterior wall of the nasopharynx was the higher. Third, patients with pathological grading III/IV were more likely to have higher survival rate than pathological grading I/II and unknown grading in CSS and OS. Taken together, these factors may play an important role in NPC patients, especially with regard to insurance. Some studies indicated that insurance status offers protection for cancer patients[14, 15], while others implied that the health insurance status is related to the mortality and presentation stage of cancer patients[16, 17]. Insurance is a socioeconomic factor and understanding how populations of cancer patients are influenced by it will better clarify how to mitigate disparities in care and outcomes[15]. In our subgroup multivariate analysis, single/unmarried patients had lower HRs than married patients, with respect to their insurance plans, while separated/windowed/divorced patients showed contrary results, because in addition to the obvious psychological stress of an unfavorable diagnosis, the lack of a spouse may also reduce their ability to pay for treatment[18]. Besides, cancer diagnosis can lead to psychological disorders (e.g., despair, loss, worry, fear, anxiety), and if patients are older and without a spouse, this will lead to poorer CSS[19] (Table 4).

Cancer treatment mainly involves surgery, radiotherapy, and chemotherapy. Previous studies based on SEER data have shown that different categories of cancer patients can benefit from different treatment 
options, and the survival rates of patients who are treated is not necessarily high[20-22]. In our study, separated/windowed/divorced patients had the lowest 5-year CSS in those that underwent surgery, radiotherapy, and/or chemotherapy, and the HRs of single/unmarried patients who received radiotherapy were even lower than married patients. The 5-year CSS was similar. Interestingly, single/unmarried surgery-naïve patients had highest 5-year CSS when surgery was performed, and the HRs of single/unmarried patients were lower than patients who received surgery and chemotherapy. The 5-year CSS of single/unmarried patients who accepted chemotherapy was similar to those that did not accept chemotherapy. These results suggest that surgery and chemotherapy are not especially important for single/unmarried patients.

Another previous SEER study by Wu et al. [10] evaluated the influence of marital status in NPC between 2004 and 2013, and the results indicated that widowed patients were associated with an increased risk of cancer mortality in NPC. However, the influence of marital status-married, unmarried, single, separated, divorced, and widowed-were not further compared in the subgroup multivariate analysis by age, sex, grade, insurance, surgery, radiation, and chemotherapy. In addition, we grouped different marital status rather than grouping them separately and included unmarried and separated patients. Our results showed that separated/widowed/divorced patients had poorer CSS than married, single/unmarried patients. However, the married and single/unmarried groups had their own advantages under different influencing factors, and there was no significant difference except with respect to no chemotherapy. Thus, our results are consistent with those from previous studies of various cancer sites showing that separated/widowed/divorced patients were more likely to increase risk of cancer mortality[23-25].

Our study has several limitations. First, the SEER program only records the marital status at the time of diagnosis, and the details of patients' marital status were not reported or tracked during treatment, which might affect the outcomes of NPC patients. Second, the classification of patient ethnicity in the SEER program is not very distinct and detailed (e.g., American Indian, AK Native, and Asian/Pacific Islanders), which may have led to an underestimation of the true impact of ethnicity on survival outcomes. Third, the SEER program lacks sufficient information about subsequent therapy, comorbidities, disease recurrence, and adjuvant therapy, and it also does not record important demographic factors such as education and income. Finally, our research is based on the US population, and the results therefore represent only $28 \%$ of all Americans, and are not a true representation of the global population.

\section{Conclusion}

Our results suggest that being separated/widowed/divorced increases the risk of NPC mortality when compared to patients who are married or single/unmarried patients. In the subgroup analysis, separated/widowed/divorced patients were regarded as a high-risk group with poor prognosis. Therefore, more social and psychosocial support should be given to cancer patients who are separated, widowed, or divorced. Furthermore, clinicians should pay more attention to patients' marital status in case of an NPC diagnosis, and provide them with an individualized care and treatment plan. 


\section{Abbreviations}

SEER: Surveillance, Epidemiology, and End Results

NPC: nasopharyngeal carcinoma;

CSS: cause-specific survival;

OS: overall survival;

HR: hazard ratio;

HNC: head and neck cancer;

Cls: confidence intervals;

TNM: tumor node metastasis

\section{Declarations}

\section{Ethics approval and consent to participate}

We got approval from the National Cancer Institute to use data of patient from SEER database.

Participant consent was not necessary as this study involved the use of a previously-published deidentified database according to SEER database.

\section{Consent for publication}

Not applicable.

\section{Availability of data and material}

The datasets generated and/or analysed during the current study are available in the SEER database, https://seer.cancer.gov/data/.

\section{Competing interests}

The authors declare no conflicts of interest.

\section{Funding}


Sichuan Provincial Health and Family Planning Commission Research Project, P. R. China (grant number: 18PJ540).

\section{Authors' contributions}

Bin Yu and Fei Lin contributed equally to this work. Bin Yu, Fei Lin, and Shan Xu conceived and designed the study. Li Qin and Hong Ning searched the databases and collected the data. Bin-wei Lin, Fei Lin, and Shan Xu analyzed and interpreted the data. Bin Yu wrote the manuscript. and Li Qin reviewed the final manuscript

\section{Acknowledgements}

The authors are thankful for the Surveillance, Epidemiology, and End Results (SEER) Program tumor registries for providing open access to the database.

This work was supported by a grant of Sichuan Provincial Health and Family Planning Commission Research Project, P. R. China (grant number: 18PJ540).

\section{References}

1.Torre LA, Bray F, Siegel RL, Ferlay J, Lortet-Tieulent J, Jemal A: Global cancer statistics, 2012. CA: a cancer journal for clinicians 2015, 65(2):87-108.

2.Chan JW, Parvathaneni U, Yom SS: Reducing radiation-related morbidity in the treatment of nasopharyngeal carcinoma. Future Oncol 2017, 13(5):425-431.

3.Hong JS, Hua YJ, Su L, Zhang HR, Lv WL, Chen XY, Tian J, Zhang WJ: Modified-Nutrition Index is a Significant Prognostic Factor for the Overall Survival of the Nasopharyngeal Carcinoma Patients who Undergo Intensity-modulated Radiotherapy. Nutr Cancer 2017, 69(7):1011-1018.

4.Karnell LH, Christensen AJ, Rosenthal EL, Magnuson JS, Funk GF: Influence of social support on healthrelated quality of life outcomes in head and neck cancer. Head \& neck 2007, 29(2):143-146.

5.Aizer AA, Chen MH, McCarthy EP, Mendu ML, Koo S, Wilhite TJ, Graham PL, Choueiri TK, Hoffman KE, Martin NE et al: Marital status and survival in patients with cancer. J Clin Oncol2013, 31(31):3869-3876.

6.Long S, Li M, Ou S, Li G: The effect of marital status on glioma patient survival: analysis of 617 cases: A SEER-based study. Medicine (Baltimore) 2018, 97(52):e13900.

7.Zhang J, Gan L, Wu Z, Yan S, Liu X, Guo W: The influence of marital status on the stage at diagnosis, treatment, and survival of adult patients with gastric cancer: a population-based study. Oncotarget 2017, 8(14):22385-22405. 
8.Osazuwa-Peters N, Christopher KM, Cass LM, Massa ST, Hussaini AS, Behera A, Walker RJ, Varvares MA: What's Love Got to do with it? Marital status and survival of head and neck cancer. European journal of cancer care 2019:e13022.

9.Xu C, Liu X, Chen YP, Mao YP, Guo R, Zhou GQ, Tang LL, Lin AH, Sun Y, Ma J: Impact of marital status at diagnosis on survival and its change over time between 1973 and 2012 in patients with nasopharyngeal carcinoma: a propensity score-matched analysis. Cancer Med 2017, 6(12):3040-3051.

10.Wu SG, Zhang QH, Zhang WW, Sun JY, Lin Q, He ZY: The Effect of Marital Status on Nasopharyngeal Carcinoma Survival: A Surveillance, Epidemiology and End Results Study. J Cancer 2018, 9(10):18701876.

11.Warren JL, Klabunde CN, Schrag D, Bach PB, Riley GF: Overview of the SEER-Medicare data: content, research applications, and generalizability to the United States elderly population. Medical care 2002, 40(8 Suppl):IV-3-18.

12.National Cancer Institute. Surveillance Research Program SSBS, epidemiology, and end results (SEER) program.: Number of persons by race and Hispanic ethnicity for SEER participants (2010 census data). In. Available at: http://seer.cancer.gov/registries/data.html (accessed June 21, 2017).

13.Huang SJ, Tang YY, Liu HM, Tan GX, Wang X, Zhang H, Yang F, Yang S: Impact of age on survival of locoregional nasopharyngeal carcinoma: An analysis of the Surveillance, Epidemiology, and End Results program database, 2004-2013. Clinical otolaryngology: official journal of ENT-UK; official journal of Netherlands Society for Oto-Rhino-Laryngology \& Cervico-Facial Surgery 2018, 43(5):1209-1218.

14.Cannon RB, Shepherd HM, McCrary H, Carpenter PS, Buchmann LO, Hunt JP, Houlton JJ, Monroe MM: Association of the Patient Protection and Affordable Care Act With Insurance Coverage for Head and Neck Cancer in the SEER Database. JAMA Otolaryngol Head Neck Surg 2018, 144(11):1052-1057.

15.Panth N, Simpson MC, Sethi RKV, Varvares MA, Osazuwa-Peters N: Insurance status, stage of presentation, and survival among female patients with head and neck cancer. The Laryngoscope 2019.

16.Inverso G, Mahal BA, Aizer AA, Donoff RB, Chuang SK: Health Insurance Affects Head and Neck Cancer Treatment Patterns and Outcomes. J Oral Maxillofac Surg 2016, 74(6):1241-1247.

17.Osazuwa-Peters N, Christopher KM, Hussaini AS, Behera A, Walker RJ, Varvares MA: Predictors of stage at presentation and outcomes of head and neck cancers in a university hospital setting. Head \& neck 2016, 38 Suppl 1:E1826-1832.

18.Phillips AC, Carroll D, Der G: Negative life events and symptoms of depression and anxiety: stress causation and/or stress generation. Anxiety, stress, and coping 2015, 28(4):357-371.

19.Kaiser NC, Hartoonian N, Owen JE: Toward a cancer-specific model of psychological distress: population data from the 2003-2005 National Health Interview Surveys. Journal of cancer survivorship: 
research and practice 2010, 4(4):291-302.

20.McLaughlin C, Kim NK, Bandyopadhyay D, Deng X, Kaplan B, Matin K, Fields EC: Adjuvant radiation therapy for T4 non-rectal colon adenocarcinoma provides a cause-specific survival advantage: A SEER database analysis. Radiotherapy and oncology: journal of the European Society for Therapeutic Radiology and Oncology 2019, 133:50-53.

21.Wei JL, Jiang YZ, Shao ZM: Survival and chemotherapy-related risk of second primary malignancy in breast cancer patients: a SEER-based study. Int J Clin Oncol 2019.

22.Lin JL, Lin JX, Li P, Xie JW, Wang JB, Lu J, Chen QY, Cao LL, Zheng CH, Huang CM: The Impact of Surgery on Long-Term Survival of Patients with Primary Gastric Diffuse Large B-Cell Lymphoma: A SEER Population-Based Study. Gastroenterol Res Pract 2019, 2019:9683298.

23.Lowery WJ, Stany MP, Phippen NT, Bunch KP, Oliver KE, Tian C, Maxwell GL, Darcy KM, Hamilton CA: Survival advantage of marriage in uterine cancer patients contrasts poor outcome for widows: a Surveillance, Epidemiology and End Results study. Gynecol Oncol 2015, 136(2):328-335.

24.Zhou R, Yan S, Li J: Influence of marital status on the survival of patients with gastric cancer. J Gastroenterol Hepatol 2016, 31(4):768-775.

25.Wang X, Li X, Su S, Liu M: Marital status and survival in epithelial ovarian cancer patients: a SEERbased study. Oncotarget 2017, 8(51):89040-89054.

\section{Tables}

Table 1. Baseline demographic and tumor characteristics of patients with nasopharyngeal carcinoma according to marital status in SEER database 


\begin{tabular}{|c|c|c|c|c|c|}
\hline Characteristic & $\begin{array}{c}\text { Total } \\
(\mathrm{n}=5477) \mathrm{N} \\
(\%) \\
\end{array}$ & $\begin{array}{c}\text { Married } \\
(\mathrm{n}=3370) \mathrm{N} \\
(\%) \\
\end{array}$ & $\begin{array}{l}\text { Single/unmarried } \\
(\mathrm{n}=1226) \mathrm{N}(\%)\end{array}$ & $\begin{array}{l}\text { Separated/widowed/divorced } \\
\qquad(\mathrm{n}=881) \mathrm{N}(\%)\end{array}$ & $\begin{array}{c}P \\
\text { value }\end{array}$ \\
\hline Gender & & & & & $<0.001$ \\
\hline Male & 3886(71.0) & $2506(74.4)$ & 887(72.3) & $493(56.0)$ & \\
\hline $\begin{array}{l}\text { Female } \\
\text { Age }\end{array}$ & 1591(29.0) & $864(25.6)$ & $339(27.7)$ & $388(44.0)$ & $<0.001$ \\
\hline$\leq 50$ & 2121(38.7) & 1242(36.9) & 697(56.9) & 182(20.7) & \\
\hline $\begin{array}{l}>50 \\
\text { Race }\end{array}$ & $3356(61.3)$ & $2128(63.1)$ & $529(43.1)$ & 699(79.3) & $<0.001$ \\
\hline White & $2529(46.2)$ & $1445(42.9)$ & $538(43.9)$ & $546(62.0)$ & \\
\hline Black & $627(11.4)$ & $224(6.6)$ & 289(23.6) & 114(12.9) & \\
\hline Other ${ }^{1}$ & 2274(41.5) & 1671(49.6) & $387(31.6)$ & $216(24.5)$ & \\
\hline $\begin{array}{l}\text { Unknown` } \\
\text { Registry Region² }\end{array}$ & $47(0.9)$ & $30(0.9)$ & $12(1.0)$ & $5(0.6)$ & $<0.001$ \\
\hline West & $3473(63.4)$ & $2269(67.3)$ & $732(59.7)$ & $472(53.6)$ & \\
\hline Northeast & $626(11.4)$ & $365(10.8)$ & 145(11.8) & 116(13.2) & \\
\hline North Central & $351(6.4)$ & 183(5.4) & $95(7.7)$ & 73(8.3) & \\
\hline $\begin{array}{l}\text { South } \\
\text { Grade }\end{array}$ & 1027(18.8) & $553(16.4)$ & $254(20.7)$ & $220(25.0)$ & $<0.001$ \\
\hline I/II & $545(10.0)$ & 299(8.9) & $121(9.9)$ & $125(14.2)$ & \\
\hline III/IV & $3108(56.7)$ & 1986(58.9) & $686(56.0)$ & $436(49.5)$ & \\
\hline $\begin{array}{l}\text { Unknown } \\
\text { Primary Site }\end{array}$ & 1824(33.3) & 1085(32.2) & $419(34.2)$ & $320(36.3)$ & 0.066 \\
\hline $\begin{array}{l}\text { Superior wall of } \\
\text { nasopharynx }\end{array}$ & $62(1.1)$ & $41(1.2)$ & $15(1.2)$ & $6(0.7)$ & \\
\hline $\begin{array}{l}\text { Posterior wall of } \\
\text { nasopharynx }\end{array}$ & $564(10.3)$ & $358(10.6)$ & 107(8.7) & $99(11.2)$ & \\
\hline $\begin{array}{l}\text { Lateral wall of } \\
\text { nasopharynx } \\
\text { Anterior wall of } \\
\text { nasopharynx }\end{array}$ & $461(8.4)$ & $306(9.1)$ & $83(6.8)$ & $72(8.2)$ & \\
\hline $\begin{array}{l}\text { Overlapping lesion } \\
\text { of nasopharynx }\end{array}$ & $56(1.0)$ & $32(0.9)$ & $13(1.1)$ & $11(1.2)$ & \\
\hline nasopharynx & 203(3.7) & $132(3.9)$ & $37(3.0)$ & $34(3.9)$ & \\
\hline
\end{tabular}




\begin{tabular}{|c|c|c|c|c|c|}
\hline T stage (AJCC6) & $4131(75.4)$ & $2501(74.1)$ & 971(79.2) & $659(74.8)$ & $<0.001$ \\
\hline T0 & $43(0.8)$ & $30(0.9)$ & $6(0.5)$ & $7(0.8)$ & \\
\hline $\mathrm{T} 1$ & 1361(24.9) & $925(27.4)$ & $250(20.4)$ & 188(21.3) & \\
\hline $\mathrm{T} 2$ & $1064(19.4)$ & $668(19.8)$ & $227(18.5)$ & $169(19.2)$ & \\
\hline T3 & $952(17.4)$ & $546(16.2)$ & 233(19.0) & 173(19.6) & \\
\hline $\mathrm{T} 4$ & $1030(18.8)$ & $577(17.1)$ & 291(23.7) & $162(18.4)$ & \\
\hline $\begin{array}{l}\text { Unknown } \\
\text { N stage (AJCC6) }\end{array}$ & $1025(18.7)$ & $624(18.5)$ & 219(17.9) & 182(20.7) & $<0.001$ \\
\hline No & $1103(20.1)$ & $681(20.2)$ & 231(18.8) & 191(21.7) & \\
\hline N1 & 1594(29.1) & $1030(30.6)$ & $311(25.4)$ & $253(28.7)$ & \\
\hline N2 & $1292(23.6)$ & $783(23.2)$ & $336(27.4)$ & 173(19.6) & \\
\hline N3 & $611(11.2)$ & $342(10.1)$ & 167(13.6) & 102(11.6) & \\
\hline $\begin{array}{l}\text { Unknown } \\
\text { M stage (AJCC6) }\end{array}$ & $877(16.0)$ & $534(15.8)$ & 181(14.8) & $162(18.4)$ & 0.005 \\
\hline M0 & $4054(74.0)$ & $2537(75.3)$ & 876(71.5) & $641(72.8)$ & \\
\hline M1 & $536(9.8)$ & $305(9.1)$ & $151(12.3)$ & $80(9.1)$ & \\
\hline $\begin{array}{l}\text { Unknown } \\
\text { Surgery performed }\end{array}$ & $887(16.2)$ & $528(12.7)$ & 199(16.2) & $160(18.2)$ & 0.032 \\
\hline Yes & $618(11.3)$ & $397(11.8)$ & $114(9.3)$ & 107(12.1) & \\
\hline $\begin{array}{l}\text { NO } \\
\text { Radiation }\end{array}$ & $4859(88.7)$ & 2973(88.2) & $1112(90.7)$ & 774(87.9) & $<0.001$ \\
\hline Yes & $4434(81)$ & 2825(83.8) & $943(76.9)$ & $666(75.6)$ & \\
\hline $\begin{array}{l}\text { No } \\
\text { Chemotherapy }\end{array}$ & 1043(19) & $545(16.2)$ & $283(23.1)$ & $215(24.4)$ & $<0.001$ \\
\hline Yes & $4178(76.4)$ & $2640(78.3)$ & $944(77.0)$ & $603(68.4)$ & \\
\hline No & $1290(23.6)$ & $730(21.7)$ & $282(23.0)$ & $278(31.6)$ & \\
\hline
\end{tabular}

1“Other” includes American Indian, AK Native, and Asian/Pacific Islander.

2“West” includes Hawaii, Greater California, Utah, New Mexico, San Francisco-Oakland, Seattle-Puget Sound, San Jose-Monterey, Los Angeles, and Alaska. "Northeast" includes New Jersey, and Connecticut. "North central” includes Detroit and Iowa. “South” includes Greater Georgia, Rural Georgia, Atlanta, Louisiana, and Kentucky.

3“Unknownr” includes TX, NA, and Blanks.

4“Unknown” includes NX, NA, and Blanks 
5“Unknown” includes NA and Blanks

Table 2. Univariate and multivariate survival analysis for evaluating the influence of marital status on nasopharyngeal carcinoma CSS in SEER database. 


\begin{tabular}{|c|c|c|c|c|c|c|}
\hline \multirow[b]{2}{*}{ Variable } & \multirow{2}{*}{$\begin{array}{l}5 \text {-year } \\
\text { CSS } \\
(\%)\end{array}$} & \multicolumn{2}{|c|}{ Univariate analysis } & \multicolumn{3}{|c|}{ Multivariate analysis } \\
\hline & & $\underset{\text { test }}{\log \operatorname{Rank}} \chi^{2}$ & $P$ value & $\begin{array}{l}\text { Hazard } \\
\text { ratio }\end{array}$ & $\begin{array}{l}\text { 95\% Confidence } \\
\text { interval }\end{array}$ & $P$ value \\
\hline Age & & 132.712 & $<0.001$ & & & \\
\hline$\leq 50$ & 96.4 & & & Reference & & \\
\hline $\begin{array}{r}>50 \\
\text { Race }\end{array}$ & 87.8 & 32.944 & $<0.001$ & 3.878 & $3.025-4.971$ & $<0.001$ \\
\hline White & 90.4 & & & Reference & & \\
\hline Black & 87.7 & & & 1.081 & $0.810-1.443$ & 0.596 \\
\hline Other & 93.6 & & & 0.560 & 0.451-0.695 & $<0.001$ \\
\hline $\begin{array}{l}\text { Unknown } \\
\text { Gender }\end{array}$ & 93.7 & 3.051 & 0.081 & 0.643 & $0.206-2.010$ & 0.448 \\
\hline Male & 91.2 & & & Reference & & \\
\hline $\begin{array}{l}\text { Female } \\
\text { Registry Region }\end{array}$ & 92.3 & 12.944 & 0.005 & 0.823 & $0.661-1.025$ & 0.081 \\
\hline West & 92.6 & & & Reference & & \\
\hline Northeast & 89.1 & & & 1.243 & $0.919-1.681$ & 0.158 \\
\hline North central & 92.2 & & & 1.121 & $0.748-1.679$ & 0.581 \\
\hline $\begin{array}{l}\text { South } \\
\text { Grade }\end{array}$ & 89.0 & 14.968 & 0.001 & 1.531 & $1.207-1.941$ & $<0.001$ \\
\hline I/II & 89.4 & & & Reference & & \\
\hline III/IV & 92.7 & & & 0.599 & $0.441-0.812$ & 0.001 \\
\hline $\begin{array}{l}\text { Unknown } \\
\text { Primary Site }\end{array}$ & 90.0 & 2.321 & 0.803 & 0.809 & $0.588-1.113$ & 0.193 \\
\hline Superior wall of nasoharynx & 93.9 & & & Reference & & \\
\hline Posterior wall of nasoharynx & 92.5 & & & 1.012 & $0.401-2.554$ & 0.980 \\
\hline Lateral wall of nasoharynx & 92.6 & & & 0.885 & $0.345-2.270$ & 0.799 \\
\hline Anterior wall of nasoharynx & 88.9 & & & 1.563 & $0.452-5.403$ & $\begin{array}{l}0.480 \\
0.927\end{array}$ \\
\hline $\begin{array}{l}\text { Overlapping wall of } \\
\text { nasoharynx }\end{array}$ & 94.1 & & & 0.953 & $0.340-2.673$ & 0.848 \\
\hline $\begin{array}{l}\text { Nasoharynx } \\
\text { T stage (AJCC6) }\end{array}$ & 91.2 & 20.224 & 0.001 & 1.090 & $0.451-2.637$ & \\
\hline T0 & 92.0 & & & Reference & & \\
\hline T1 & 93.1 & & & 1.118 & $0.355-3.528$ & 0.849 \\
\hline T2 & 92.4 & & & 1.344 & $0.425-4.249$ & 0.615 \\
\hline
\end{tabular}




\begin{tabular}{|c|c|c|c|c|c|c|}
\hline T3 & 89.4 & & & 1.755 & $0.554-5.559$ & 0.339 \\
\hline T4 & 92.3 & & & 1.852 & $0.585-5.866$ & 0.295 \\
\hline $\begin{array}{l}\text { Unknown } \\
\text { N stage (AJCC6) }\end{array}$ & 88.1 & 28.706 & $<0.001$ & 1.969 & $0.618-6.278$ & 0.252 \\
\hline No & 90.0 & & & Reference & & \\
\hline N1 & 92.1 & & & 0.822 & $0.637-1.062$ & 0.134 \\
\hline N2 & 94.8 & & & 0.623 & $0.463-0.837$ & 0.002 \\
\hline N3 & 91.1 & & & 0.915 & $0.639-1.309$ & 0.626 \\
\hline $\begin{array}{l}\text { Unknown } \\
\text { M stage (AJCC6) }\end{array}$ & 83.7 & 11.611 & 0.003 & 1.514 & $1.096-2.091$ & 0.012 \\
\hline M0 & 92.2 & & & Reference & & \\
\hline M1 & 88.3 & & & 1.457 & $1.004-2.114$ & 0.048 \\
\hline $\begin{array}{l}\text { Unknown } \\
\text { Insurance }\end{array}$ & 86.9 & 2.172 & 0.338 & 1.550 & $1.160-2.072$ & 0.003 \\
\hline Insured/medicaid & 92.3 & & & Reference & & \\
\hline Uninsured & 92.8 & & & 1.257 & $0.733-2.155$ & 0.406 \\
\hline $\begin{array}{l}\text { Unknown } \\
\text { Surgery performed }\end{array}$ & 89.8 & 1.022 & 0.312 & 1.156 & $0.930-1.435$ & 0.191 \\
\hline Yes & 90.7 & & & Reference & & \\
\hline $\begin{array}{l}\text { NO } \\
\text { Radiation }\end{array}$ & 91.7 & 64.744 & $<0.001$ & 1.168 & 0.864-1.578 & 0.313 \\
\hline Yes & 92.8 & & & Reference & & \\
\hline $\begin{array}{l}\text { No } \\
\text { Chemotherapy }\end{array}$ & 83.8 & 59.195 & $<0.001$ & 2.460 & 1.961-3.086 & $<0.001$ \\
\hline Yes & 93.5 & & & Reference & & \\
\hline $\begin{array}{l}\text { No } \\
\text { Marital status }\end{array}$ & 83.9 & 53.198 & $<0.001$ & 2.180 & $1.778-2.674$ & $<0.001$ \\
\hline Married & 92.6 & & & Reference & & \\
\hline Single/unmarried & 92.4 & & & 0.811 & $0.675-1.152$ & 0.355 \\
\hline Separated/windowed/divorced & 85.1 & & & 2.180 & $1.727-2.751$ & $<0.001$ \\
\hline
\end{tabular}

Table 3. Univariate and multivariate survival analysis for evaluating the influence of marital status on nasopharyngeal carcinoma OS in SEER database. 


\begin{tabular}{|c|c|c|c|c|c|c|}
\hline \multirow[b]{2}{*}{ Variable } & \multirow{2}{*}{$\begin{array}{c}\text { 5-year } \\
\text { CSS } \\
(\%) \\
\end{array}$} & \multicolumn{2}{|c|}{ Univariate analysis } & \multicolumn{3}{|c|}{ Multivariate analysis } \\
\hline & & $\begin{array}{l}\log \operatorname{Rank} \chi^{2} \\
\text { test }\end{array}$ & $P$ value & $\begin{array}{l}\text { Hazard } \\
\text { ratio }\end{array}$ & $\begin{array}{l}\text { 95\% Confidence } \\
\text { interval }\end{array}$ & $P$ value \\
\hline Age & & 255.358 & $<0.001$ & & & \\
\hline$\leq 50$ & 68.1 & & & Reference & & \\
\hline$>50$ & 48.0 & & & 2.057 & $1.878-2.253$ & $<0.001$ \\
\hline Race & & 129.633 & $<0.001$ & & & \\
\hline White & 51.6 & & & Reference & & \\
\hline Black & 46.3 & & & 1.060 & 0.935-1.201 & 0.364 \\
\hline Other & 63.1 & & & 0.628 & 0.574-0.688 & $<0.001$ \\
\hline Unknown & 83.0 & & & 0.291 & $0.139-0.612$ & 0.001 \\
\hline Gender & & 14.878 & $<0.001$ & & & \\
\hline Male & 54.0 & & & Reference & & \\
\hline Female & 60.7 & & & 0.834 & $0.760-0.915$ & $<0.001$ \\
\hline Registry Region & & 35.353 & $<0.001$ & & & \\
\hline West & 58.2 & & & Reference & & \\
\hline Northeast & 53.3 & & & 1.116 & $0.979-1.272$ & 0.100 \\
\hline North central & 58.5 & & & 1.015 & $0.850-1.211$ & 0.870 \\
\hline South & 49.0 & & & 1.355 & $1.223-1.501$ & $<0.001$ \\
\hline Grade & & 99.775 & $<0.001$ & & & \\
\hline $\mathrm{I} / \mathrm{II}$ & 43.5 & & & Reference & & \\
\hline III/IV & 60.5 & & & 0.565 & $0.498-0.642$ & $<0.001$ \\
\hline Unknown & 51.9 & & & 0.769 & $0.674-0.878$ & $<0.001$ \\
\hline Primary Site & & 38.424 & $<0.001$ & & & \\
\hline Superior wall of nasoharynx & 68.8 & & & Reference & & \\
\hline Posterior wall of nasoharynx & 63.5 & & & 1.271 & $0.794-2.033$ & 0.317 \\
\hline Lateral wall of nasoharynx & 66.6 & & & 1.073 & $0.665-1.730$ & 0.773 \\
\hline Anterior wall of nasoharynx & 43.3 & & & 1.986 & 1.104-3.572 & 0.022 \\
\hline Overlapping wall of & 53.0 & & & 1.609 & $0.979-2.645$ & \\
\hline nasonarynx & 53.8 & & & 1.625 & $1.034-2.554$ & 0.035 \\
\hline $\begin{array}{l}\text { Nasoharynx } \\
\text { T stage (AJCC6) }\end{array}$ & & 297.469 & $<0.001$ & & & \\
\hline T0 & 73.0 & & & Reference & & \\
\hline $\mathrm{T} 1$ & 69.3 & & & 0.984 & $0.578-1.675$ & 0.952 \\
\hline $\mathrm{T} 2$ & 64.0 & & & 1.216 & $0.714-2.072$ & 0.472 \\
\hline
\end{tabular}




\begin{tabular}{|c|c|c|c|c|c|c|}
\hline T3 & 49.4 & & & 1.939 & $1.139-3.299$ & 0.015 \\
\hline $\mathrm{T} 4$ & 43.7 & & & 2.379 & $1.400-4.044$ & 0.001 \\
\hline $\begin{array}{l}\text { Unknown } \\
\text { N stage (AJCC6) }\end{array}$ & 42.2 & 110.256 & $<0.001$ & 2.269 & $1.331-3.869$ & 0.003 \\
\hline No & 58.2 & & & Reference & & \\
\hline N1 & 62.3 & & & 0.887 & $0.788-0.998$ & 0.046 \\
\hline $\mathrm{N} 2$ & 57.7 & & & 0.968 & $0.856-1.094$ & 0.602 \\
\hline N3 & 44.4 & & & 1.413 & $1.227-1.628$ & $<0.001$ \\
\hline $\begin{array}{l}\text { Unknown } \\
\text { M stage (AJCC6) }\end{array}$ & 40.3 & 613.753 & $<0.001$ & 1.624 & $1.406-1.877$ & $<0.001$ \\
\hline M0 & 62.5 & & & Reference & & \\
\hline M1 & 18.2 & & & 3.556 & 3.189-3.964 & $<0.001$ \\
\hline $\begin{array}{l}\text { Unknown } \\
\text { Insurance }\end{array}$ & 43.7 & 33.728 & $<0.001$ & 1.752 & $1.547-1.985$ & $<0.001$ \\
\hline Insured/medicaid & 59.0 & & & Reference & & \\
\hline Uninsured & 40.9 & & & 1.610 & $1.331-1.949$ & $<0.001$ \\
\hline $\begin{array}{l}\text { Unknown } \\
\text { Surgery performed }\end{array}$ & 50.9 & 20.836 & $<0.001$ & 1.188 & $1.084-1.303$ & $<0.001$ \\
\hline Yes & 63.5 & & & Reference & & \\
\hline $\begin{array}{l}\text { NO } \\
\text { Radiation }\end{array}$ & 55.0 & 652.423 & $<0.001$ & 1.375 & $1.198-1.579$ & $<0.001$ \\
\hline Yes & 62.4 & & & Reference & & \\
\hline $\begin{array}{l}\text { No } \\
\text { Chemotherapy }\end{array}$ & 28.2 & 184.535 & $<0.001$ & 3.035 & $2.274-3.322$ & $<0.001$ \\
\hline Yes & 59.9 & & & Reference & & \\
\hline $\begin{array}{l}\text { No } \\
\text { Marital status }\end{array}$ & 42.9 & 176.318 & $<0.001$ & 1.831 & $1.675-2.002$ & $<0.001$ \\
\hline Married & 60.7 & & & Reference & & \\
\hline Single/unmarried & 54.6 & & & 1.219 & $1.100-1.351$ & $<0.001$ \\
\hline Separated/windowed/divorced & 40.1 & & & 1.977 & $1.784-2.191$ & $<0.001$ \\
\hline
\end{tabular}

Table 4. Univariate and multivariate analysis of marital status on nasopharyngeal carcinoma CSS according to different cancer stage. 


\begin{tabular}{|c|c|c|c|c|c|c|}
\hline \multirow[b]{2}{*}{ Variable } & \multirow{2}{*}{$\begin{array}{c}\text { 5-year } \\
\text { CSS } \\
(\%) \\
\end{array}$} & \multicolumn{2}{|c|}{ Univariate analysis } & \multicolumn{3}{|c|}{ Multivariate analysis } \\
\hline & & $\underset{\text { test }}{\log \operatorname{Rank}} \chi^{2}$ & $\begin{array}{c}P \\
\text { value }\end{array}$ & $\begin{array}{l}\text { Hazard } \\
\text { ratio }\end{array}$ & $\begin{array}{l}\text { 95\% Confidence } \\
\text { interval }\end{array}$ & $\begin{array}{c}P \\
\text { value }\end{array}$ \\
\hline Age & & 15.474 & $<0.001$ & & & \\
\hline \multicolumn{7}{|l|}{$\leq 50$} \\
\hline Married & 97.1 & & & Reference & & \\
\hline Single/unmarried & 95.8 & & & 1.499 & $0.907-2.477$ & 0.114 \\
\hline & 93.2 & & & 3.251 & $1.756-6.020$ & $<0.001$ \\
\hline separated/windowed/divorced & & 18.399 & $<0.001$ & & & \\
\hline \multirow{3}{*}{$\begin{array}{l}\text { Married } \\
\text { Single/unmarried }\end{array}$} & 89.4 & & & Reference & & \\
\hline & 86.5 & & & 1.055 & $0.759-1.467$ & 0.748 \\
\hline & 82.4 & & & 1.710 & $1.330-2.198$ & $<0.001$ \\
\hline $\begin{array}{l}\text { Separated/windowed/divorced } \\
\text { Gender }\end{array}$ & & 40.422 & $<0.001$ & & & \\
\hline \multicolumn{7}{|l|}{ Male } \\
\hline Married & 92.3 & & & Reference & & \\
\hline Single/unmarried & 91.5 & & & 0.932 & $0.690-1.259$ & 0.646 \\
\hline & 84.0 & & & 2.352 & $1.766-3.134$ & $<0.001$ \\
\hline & & 19.444 & $<0.001$ & & & \\
\hline & 93.4 & & & Reference & & \\
\hline \multirow{2}{*}{ Single/unmarried } & 94.6 & & & 0.737 & $0.410-1.325$ & 0.308 \\
\hline & 86.6 & & & 2.174 & $1.438-3.285$ & $<0.001$ \\
\hline $\begin{array}{l}\text { Separated/windowed/divorced } \\
\text { Grade }\end{array}$ & & 0.572 & 0.571 & & & \\
\hline \multicolumn{7}{|l|}{$\mathrm{I} / \mathrm{II}$} \\
\hline Married & 89.2 & & & Reference & & \\
\hline Single/unmarried & 89.4 & & & 0.744 & $0.329-1.684$ & 0.479 \\
\hline & 89.9 & & & 0.865 & 0.414-1.806 & 0.699 \\
\hline & & 34.830 & $<0.001$ & & & \\
\hline $111 / 18$ & 93.8 & & & Reference & & \\
\hline & 93.0 & & & 0.941 & $0.655-1.352$ & 0.742 \\
\hline & 86.1 & & & 2.443 & $1.768-3.376$ & $<0.001$ \\
\hline
\end{tabular}


Separated/windowed/divorced

Unknown

Married

Single/unmarried

Separated/windowed/divorced Insurance

Insured/medicaid

Married

Single/unmarried

Separated/windowed/divorced

Uninsured

Married

Single/unmarried

Separated/windowed/divorced

Unknown

Married

Single/unmarried

Separated/windowed/divorced Surgery performed

Yes

Married

Single/unmarried

Separated/windowed/divorced

NO

Married

Single/unmarried

Separated/windowed/divorced Radiation
$25.004<0.001$
91.2

92.0

81.6
Reference

$$
0.856
$$

2.356

0.506

1.610-3.449

$<0.001$
$0.542-1.352$
93.0

92.8

87.8

91.9

94.0

93.2

91.8

90.9

79.3

92.5

89.9

84.3

92.6

92.7

85.6
$28.627<0.001$

Reference

0.910

$0.649-1.276$

0.584

2.136

1.573-2.902

$<0.001$

$0.592 \quad 0.744$

Reference

0.908

0.277-2.976

0.873

1.556

$0.388-2.246$

0.533

$24.538<0.001$

Reference

0.801

0.494-1.297

0.367

2.293

1.582-3.325

$<0.001$
Reference

1.592

0.758-3.345

0.220

$46.992<0.001$

1.378-5.066
$<0.001$

Reference
0.812

0.609-1.082

0.155

2.142

1.667-2.751

$<0.001$
$43.806<0.001$ 
Yes

Married

Single/unmarried

Separated/windowed/divorced

No

Married

Single/unmarried

Separated/windowed/divorced Chemotherapy

Yes

Married

Single/unmarried

Separated/windowed/divorced

No

Married

Single/unmarried
93.8

93.6

86.4

83.7

86.5

78.5

94.8

92.5

88.7

84.0.

92.0

72.9
Reference

$\begin{array}{lll}0.884 & 0.647-1.209 & 0.441\end{array}$

2.254

$1.727-2.942$

$<0.001$

$$
8.950 \quad 0.011
$$

Reference

$\begin{array}{lll}0.717 & 0.427-1.206 & 0.210\end{array}$

$\begin{array}{lll}1.719 & 1.061-2.785 & 0.028\end{array}$
Reference

1.122

2.192

$25.093<0.001$

Reference

0.461

$0.258-0.826$

0.009

1.946

$1.329-2.850$

0.001

Separated/windowed/divorced

\section{Figures}


Patients diagnosed with NPC between 2004 and $2016(\mathrm{n}=7380)$

Excluded:

1.Age at diagnosis $<18$ years-old or unknown $(n=180)$

2.Unknown cause survival month $(\mathrm{n}=58)$

3.Unknown marital status $(\mathrm{n}=449)$

4.None of one primary site $(\mathrm{n}=1216)$

Included in the analysis $(\mathrm{n}=5477)$

Figure 1

Flow diagram depicting the inclusion and exclusion criteria for patients 


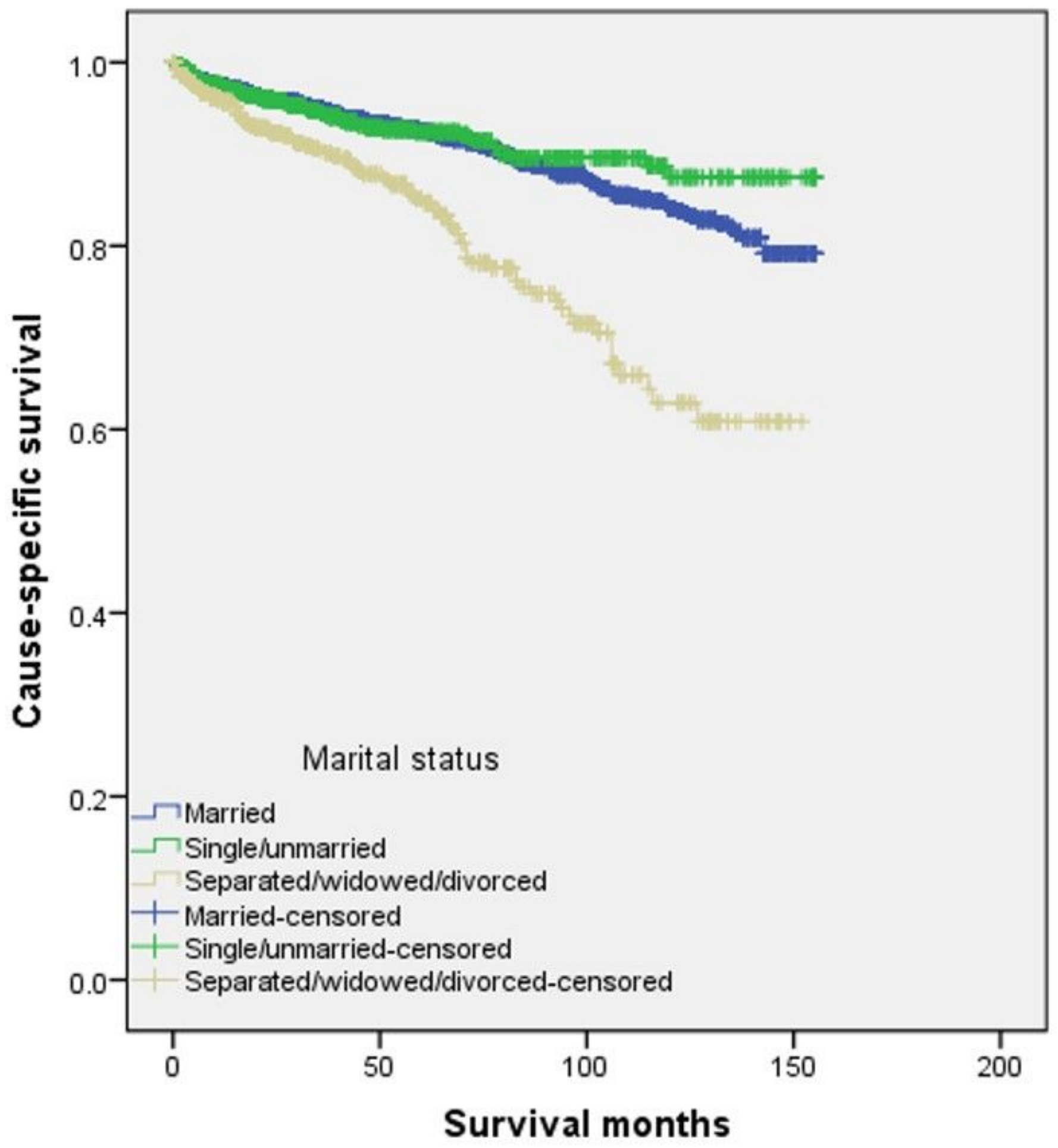

Figure 2

Survival curves for cause-specific survival (CSS) in patients with nasopharyngeal carcinoma according to marital status $(X 2=53.198, P<0.001)$. 


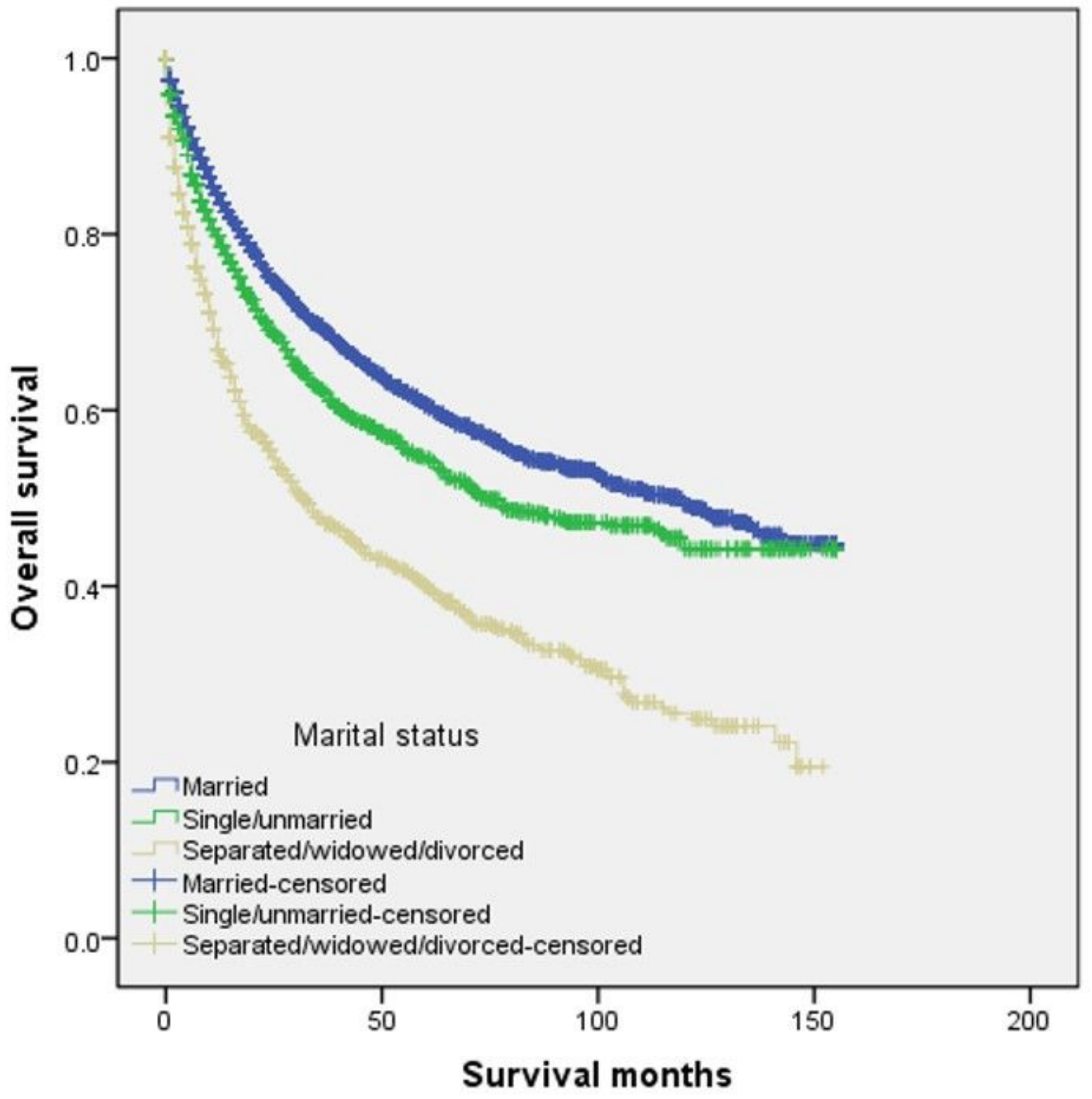

Figure 3

Survival curves for overall survival (OS) in patients with nasopharyngeal carcinoma according to marital status $(X 2=153.856, P<0.001)$. 